REVISTA ANDALUZA DE ANTROPOLOGÍA

NÚMERO 16: REFLEXIONES CONTEMPORÁNEAS SOBRE ABORDAJE DE LO RELIGIOSO, EL PATRIMONIO CULTURAL Y TURISMO RELIGIOSO

MARZO DE 2019

ISSN 2174-6796

[pp. 1-20]

http://dx.doi.org/10.12795/RAA.2019.i16.01

\title{
NUEVOS PROBLEMAS DE LA ANTROPOLOGÍA DE LAS RELIGIONES
}

\section{NEW PROBLEMS OF THE ANTHROPOLOGY OF RELIGIONS}

Elio Masferrer Kan

ENAH-INAH

\section{Resumen.}

Analiza los nuevos problemas de investigación de la antropología de las religiones en sociedades complejas, define las características de los nuevos actores sociales y la complejidad de los nuevos contextos económicos sociales y políticos. Realiza una crítica a las teorías de la secularización y propone una estrategia desde el Sur.

Palabras clave. Antropología de las religiones, secularización, contexto social, contexto político.

\section{Abstract.}

It analyzes the new research problems of the anthropology of religions in complex societies, defines the characteristics of the new social actors and the complexity of the new contexts. Criticizes the theories of secularization and proposes a strategy from the South.

Key words.

Anthropology of Religions, secularization, social context, political context. 


\section{Introducción}

La mejor explicación de lo que hace un antropólogo la escuché de Tom Zuidema, quien revolucionaría los estudios del mundo andino. "Cuando llegué a los Andes todo parecía caótico y sin sentido, el desafío fue encontrar las nociones organizativas y estructurales que le dan sentido a ese caos aparente". Ese fue y es mi programa. Al principio cuando inicié mis investigaciones sobre la cuestión religiosa trataba de encontrar las "llaves que abrieran el cofre"; necesitaba una pregunta. Me la dio una frase de la Dra. Alicia Puente de Guzmán, académica y militante católica, quien dijo: "México es un país esquizofrénico, es de los más católicos y creyentes del mundo y es donde peor se trata a la Iglesia Católica”. Responder a esa pregunta-afirmación fue lo que me llamó a buscar la noción de campo religioso mexicano, descubrir sus claves estructurales y eso (considero que) lo hice en ¿Es del Cesar o es de Dios? Un modelo antropológico del campo religioso (2004), Religión, poder y cultura (2009), Pluralidad religiosa en México (2011) y Religión, política y metodologías (2014).

El problema más complejo que tenemos actualmente en la antropología es la construcción de propuestas conceptuales, teóricas y metodológicas que nos permitan afrontar los desafíos de los nuevos procesos sociales, culturales y económicos, de las nuevas formas de dominación, de los procesos de resistencia y de construcción de nuevas propuestas culturales que expresen la diversidad y los procesos de creación de nuevas propuestas culturales y subculturales basadas, no sólo en la articulación a los procesos productivos, sino también a los diferentes modos de consumo, en situación donde los procesos de préstamo cultural y aculturación han adquirido una dinámica muy peculiar que algunos autores proponen un nuevo concepto, el de hibridación.

El impacto de las políticas neoliberales, de la economía-mundo han trastocado los paradigmas del siglo XIX y XX. Antes podíamos hablar de países metropolitanos, dependientes, coloniales y neocoloniales. Recordemos los aportes de dos antropólogos mexicanos, Rodolfo Stavenhagen y Pablo González Casanova quienes propusieron en su momento los conceptos de colonialismo interno e interculturalidad. En el siglo XXI la dinámica y triunfo del capital financiero sobre el capital industrial nos ha llevado a que los procesos de colonialismo interno, son procesos "no localizados" donde los paraísos fiscales juegan un papel estratégico que lleva a que podemos aplicar esas mismas categorías de colonialismo y dependencia a los antiguos países metropolitanos. Ya no podemos decir que "lo que es bueno para la General Motors es bueno para los Estados Unidos”. También en los Estados Unidos y Europa hay procesos de colonialismo interno.

La altísima concentración de capital financiero demostrada por Thomas Piketty se hace en base al empobrecimiento de las grandes mayorías, estén donde estén. En España, en Grecia, en Francia o los Estados Unidos. Esta situación es más grave todavía en 
los antiguos países dependientes y coloniales donde su propia situación estructural les impide cualquier respuesta adecuada, transformándose nuevamente en simples proveedores de materias primas, de acuerdo a las necesidades de la "economía-mundo". Esta situación lleva a nuevas contradicciones, ya en los años sesenta del siglo pasado, un sociólogo, José Nun, había planteado que los cambios estructurales llevaban a que perdiera vigencia el concepto de "ejercito industrial de reserva", sin descartarlo en ciertas situaciones específicas, planteaba el desarrollo de una "masa marginal", que no tenía ninguna posibilidad de articularse al proceso productivo. Esta situación está agravada por el desarrollo de los procesos de automatización, digitalización y robotización, que se articula con los procesos de outsorcing y de "deslocalización" de los procesos productivos.

Los antropólogos nos vemos también cuestionado por las nuevas mecánicas de ruralización y desruralización, más las dinámicas propias de los procesos de urbanización y de metropolización que transforman las relaciones sociales, familiares y estructurales, llevándonos al desarrollo de nuevas configuraciones culturales, donde en los procesos de endoculturación inciden los medios de información de masas que en muchos casos imponen construcciones culturales de otros contextos, muy lejanos de las realidades que les toca vivir a los grupos sociales con quienes interactuamos. En muchos casos estos "aportes" culturales externos participan en la construcción de la cultura ideal y las utopías "propias" incidiendo en procesos de enajenación cultural.

\section{La antropología, la antropología de las religiones y las religiones. Una lectura desde América Latina.}

Las nuevas realidades estructurales y culturales nos plantean nuevas preguntas a la vez que nos llevan a percibir la reformulación de los sistemas religiosos. Algunos colegas, la mayoría de ellos intelectuales orgánicos de las iglesias y grupos políticos, erraron el camino al considerar que el abandono de las prácticas y creencias religiosas tradicionales llevaban a la consolidación de la increencia y los procesos de secularización. La aplicación mecánica de ciertos intelectuales y pensadores europeos los llevó a predecir la muerte de Dios y el desencantamiento del mundo. Las expectativas eran que con el desarrollo científico y los procesos de industrialización las propuestas religiosas entrarían en crisis y decadencia.

\section{Las guerras europeas del siglo $\mathrm{XX}$ en la construcción de imaginarios sociales $\mathrm{y}$ religiosos}

Desconcierta a un observador externo a la situación europea que los científicos sociales de las religiones de ese continente no tienen como variables en la construcción de los "imaginarios europeos" contemporáneos, el exterminio en los campos, el impacto de las dos guerras mundiales y los millones de muertos, "la guerra de trincheras" más la destrucción y bombardeo implacable a sus principales ciudades, lo considero un 
mecanismo de negación, un acuerdo implícito: "de eso no se habla". Davie se refiere simplemente al impacto de la industrialización y la urbanización. Aunque ella nació en 1943 ¿Su padre fue movilizado durante la guerra? ¿Su ciudad fue bombardeada? Es interesante destacar que en un alarde de larguísima duración (Braudel, 1980) se remitían a la Reforma de hacía 470 años, pero no a lo sucedido hacía 45 años.

Es probable que muchos europeos se pregunten ¿dónde estaba Dios "en esos días"? Ese fue el desafío para las iglesias y pudiéramos suponer que el abandono de la asistencia a las mismas es resultado de las dificultades de las iglesias para construir respuestas pertinentes. Ofrezco las Actas de la XIX Conferencia a quién las quiera consultar, que los sociólogos europeos no incluyen como variables para investigar en ninguna de sus disertaciones si la familia secularizada o re-encantada o desencantada había tenido muertos en la Guerra, en los campos de exterminio, si su casa había sido destruida por los bombardeos, con o sin sus familiares, si su madre o su hermana habían sido violadas por los soldados invasores del país que fuere, si había pasado hambre, etc. Los científicos de la religión europeos evidentemente omiten las variables traumáticas y no las mencionaban por "delicadeza", evitaban mencionar "cosas incómodas", solo algunos miembros de la Escuela de Franckfort como Adorno lo hacían o un filósofo español, que no es judío, explicó "Genocidios ha habido muchos, pero la humanidad los había digerido como precio obligado del progreso. La singularidad de Auschwitz[es]haber llevado a la conciencia de la humanidad la inmoralidad de esa lógica histórica" (Reyes Mates, 2007:11).

La discusión fue sintetizada, por si quedaba alguna duda, en una excelente y sorprendente conferencia magistral de José V. Casanova en la Universidad Pública de Navarra el 14 de octubre de 2010, donde mostró la ambivalencia del concepto de secularización, y sus diferencias entre Europa y Estados Unidos, concluyendo que en este la laicidad y la secularización fortalecen las religiones, mientras que en Europa sucedería lo contrario. Llama la atención su síntesis del siglo XX, un "siglo corto", entre 1914 y 1989, donde planteo que las guerras de este período deben entenderse como procesos políticos de construcción del estado moderno, "no son guerras de religión", dijo textualmente refiriéndose explícitamente como tales a las del 1525 a 1648. Desconcierta que un español no mencione la Guerra Civil Española, "que se hizo en nombre de Dios" y el exterminio de judíos y testigos de Jehová por los nazis. Cabe recordar que el nazismo se configuró como una propuesta política orientada por el odio contra los judíos, como se desprende de Mi lucha, el documento programático de Adolfo Hitler.

El problema era y es epistemológico, los sociólogos europeos de la CISR (ISSR) partían de una concepción epistemológica que divide entre religiones "naturales" (la de los indígenas americanos o cosmoteístas) y "reveladas", las grandes religiones monoteístas (Assmann, 
2006, 2008). Desde este concepto de revelación, es que hablan de la dialéctica religión (lo revelado) y religiosidades: la dimensión humana de la creencia. Lo que estudiamos los antropólogos de las religiones sería esto último, a lo que llamamos sistema religioso. Las revelaciones divinas no vamos a discutir si existen o no, esa es tarea de los teólogos y/ de los sociólogos-teólogos, intelectuales orgánicos de las iglesias. Los hombres, en esta perspectiva epistemológica fenomenológica, no pueden cuestionar a Dios, este sería "permanente e inmutable", "Él sabe lo que hace". Sería una "blasfemia cuestionar a Dios". “Dónde estaba?, por favor, siempre estuvo". Dudar de Dios, de su existencia, de su no involucramiento y "que por qué deja a la deriva al creyente", en el medio de un campo de concentración o durante un bombardeo u otras situaciones traumáticas sería no ser creyente. Por ello nuestros teólogos-sociólogos consideraban fuera de su campo de investigación a todo el que no estuviera convencido de la omnipotencia de Dios y omnipresencia de Dios, su investigación estaba limitada a los creyentes, como si todos los "creyentes" coincidieran con su definición teológica y como si las multitudes que antes de la Guerra iban a los templos fueran o hayan sido creyentes de acuerdo a esta definición teológica.

Dividir entre religiones reveladas y naturales para cualquier antropólogo es una concepción etnocéntrica y eurocéntrica, pues los europeos no les conceden a las religiones americanas un estatus adecuado debido a que no tienen "un libro". Sintetizando, lo religioso está relacionado con la "trascendencia" para los fenomenólogos, pero para los antropólogos, la trascendencia es una característica de ciertas religiones y no de todas, por ello nos parece más adecuada la definición de Geertz: "un sistema de símbolos que obra para establecer vigorosos, penetrantes y duraderos estados anímicos y motivaciones en los hombres, formulando concepciones de un orden general de existencia y revistiendo estas concepciones con una aureola de efectividad tal que los estados anímicos y motivaciones parezcan de un realismo único" (Geertz, 1989: 89).

\section{Un "paseo académico" por el Primer Mundo}

Una cuestión que llama poderosamente la atención es el empleo por varios especialistas en sociología, historia y antropología de las religiones de un bagaje conceptual, que a veces que trata de ser novedoso de categorías desarrolladas entre Estados Unidos y Europa, a lo largo del siglo XX, donde las categorías analíticas aparecen formuladas en muchos casos en el período inmediatamente posterior a la Segunda Guerra Mundial. Un ejemplo paradigmático es el concepto de secularización, planteado por los sociólogos de la religión en los años sesenta. En esa misma década, la Iglesia Católica convocó al Concilio Vaticano II que se propuso el aggiornamento (actualización o "puesta al día") de la Iglesia. Algunos analistas plantean como oponentes de la secularización a los planteos de la Iglesia Católica, empleando como sinónimos, secularización a increencia o apostasía, 
otros asimilan secularización a incremento de la laicidad, asumiendo como indicador la toma de "distancia" entre la Iglesia Católica y el Estado. En esta perspectiva siempre me pareció muy sugerente las propuestas casi antropológicas de Karel Dobbelaere (19811994). Es importante comentar la visión sintética de Grace Davie una socióloga de la religión británica que ha trabajado también en Estados Unidos, donde fue presidenta de la American Association for the Sociology of Religion (2003):

"Lo manifiesto era que las estructuras tradicionales de la vida religiosa, profundamente enraizadas en el orden económico y político de la Europa premoderna, se estaban derrumbando bajo la doble presión sinérgica de la industrialización y la urbanización. El proceso en sí resulta ya significativo para el desarrollo de la sociología. Sin embargo, mayor alcance iban a tener todavía las implicaciones conceptuales que habrían de acompañarlo, puesto que la sociología no sólo andaba a la caza de fórmulas que le permitieran describir el «daño» que se estaba generando, sino también de vías para explicarlo. A esta luz ha de verse el abrumador predominio de la preocupación asociada con la consideración de que, en efecto, la secularización era el paradigma dominante en el ámbito de la sociología de la religión” Davie, 2007-11:12-13)

En Europa, terminada la Segunda Guerra Mundial las administraciones eclesiásticas comenzaron a interrogar a los sociólogos, quienes en su mayoría eran muy institucionales, sobre las razones de la disminución de feligreses en los templos. Se asumió la secularización como abandono de las prácticas religiosas. Esta situación se mantiene en Europa occidental y en Canadá, las iglesias han pasado a cerrar iglesias y conventos y en muchos casos a venderlos. Es público que la Iglesia Católica alemana, al igual que la Iglesia Luterana tienen sendos portales donde ofrecen en venta estos activos inmobiliarios. Incluso en Estados Unidos, las investigaciones realizadas por Pew Research señalan el incremento de la increencia en los jóvenes de ese país. Nuestra hipótesis de trabajo consiste en que secularización implica "puesta en el siglo" o actualización de una propuesta religiosa, sin que ello implique abandono o negación de las creencias religiosas, esa es otra cuestión. Aunque nos hacemos también la pregunta de las causas de ello. Es interesante la explicación de Dobbelaere y Davie, eluden cualquier mención a las grandes guerras europeas del siglo XX.

\section{En torno al contexto contemporáneo}

Tenemos frente a nosotros nuevas realidades que no coinciden con nuestros colegas, tanto los europeos como los eurocéntricos latinoamericanos. El abandono de las tradiciones católicas responde a causas endógenas y exógenas, no podemos dejar de mencionar la crisis de credibilidad resultado de las poco atendidas denuncias de abusos del clero, la incapacidad para responder a los nuevos desafíos culturales y estructurales más el clericalismo asfixiante que impide el involucramiento constructivo e innovador de los 
laicos en las cuestiones organizativas y doctrinales del catolicismo. Sumado al alejamiento de las propuestas de la Iglesia Católica de las nuevas necesidades y problemas de las sociedades, extirpando y descartando los intentos renovadores del Concilio Vaticano II.

Las respuestas de las sociedades latinoamericanas se mueven en dos grandes espacios, la pérdida de creencias religiosos y la configuración del mundo evangélico. Una respuesta estructural a la descomposición en el largo plazo del catolicismo como religión de Estado. El mundo evangélico tiene una gran diversidad y como científicos sociales de las religiones debemos evitar cualquier tentación reduccionista. El problema más complejo de los investigadores latinoamericanos, provenientes de países donde el catolicismo fue religión de estado, a la vez que "estructura del sistema cultural", es tomar y construir una distancia objetiva que nos permita apreciar el proceso, "quitándonos" los lentes culturales del catolicismo. Esto es al margen de la religión en la que hayamos sido iniciado e incluye a quienes no fuimos iniciados en ninguna.

\section{Una propuesta desde el Sur}

Nuestra propuesta conceptual de trabajar "desde el Sur" se refiere a que la construcción de los conceptos en antropología y ciencias sociales deben estar referidos a su contexto de desarrollo. Es interesante recordar que los sociólogos de la religión europeos trataron de explicarse el abandono de la religión, el descuido de las prácticas religiosas en Europa como un fenómeno generacional, tomando la categoría weberiana de desencantamiento del mundo, como un ascenso de la racionalidad sobre las creencias. Lo que propuso un importante y lúcido sociólogo como Max Weber se transformó en una "verdad prácticamente irrefutable", es importante recordar que este autor planteó dicho concepto en el período entre ambas guerras mundiales. Según esta lógica "deductiva" el mundo occidental atravesaría un fuerte proceso de secularización y abandono de lo religioso y en esta perspectiva América Latina "seguramente" debería atravesar un proceso de secularización y desencantamiento del mundo, como resultado de la modernización.

Esta aceptación y aplicación acrítica y atemporal de paradigmas sociológicos construidos en los contextos europeos por sociólogos y antropólogos latinoamericanos son una expresión contemporánea de ideologías neocoloniales, que se expresan en nuestra disciplina en la posición hegemónica de estudiantes-graduados formados en Europa y Norteamérica, quienes se ubican en posiciones "ventajosas" en las universidades y centros académicos de nuestra Región. Generando de alguna manera una posición de "codificación" y valoración del trabajo de sus colegas, quienes son obligados a emplear sus paradigmas, que estos grupos hegemónicos consideran los "auténticos" y "verdaderos", más aún los configuran en un ambiente de "no refutabilidad" que lleva a una situación de aparente "verdad" que se asemeja a un dogma religioso, precisamente el impacto de lo que pretendemos estudiar en nuestras poblaciones. 
Esto es notorio en las Conferencias Internacionales de Sociología de las Religiones, donde por la mañana los participantes debíamos escuchar "disciplinadamente" a un grupo de expositores considerados como quienes "marcan la línea" y por la tarde los "ponentes cautivos" exponíamos nuestros free papers en simposios simultáneos, donde los expositores teníamos la felicidad de escucharnos a nosotros mismos, en este ambiente "consagrado", pues la posibilidad de intercambio era mínima. Este modelo ha sido replicado por las Jornadas de Alternativas Religiosas del Mercosur y a un nivel más vernáculo por la Red de Investigadores del Fenómeno Religioso en México, donde las "cabezas de equipo" locales llevan a sus "tesistas cautivos" y bajo pena de "excomunión académica" les prohíben que los mismos asistan a espacios académicos "no consagrados", esto incluye la prohibición de citar autores "inconvenientes".

Estos ambientes académicos son descritos nuevamente por Grace Davie, quien ratifica mis impresiones sobre el "establecimiento" académico:

"Dos de los diez que acabo de mencionar (uno de Filipinas y el otro del África occidental) expusieron un relato significativamente similar en relación con el paradigma de la secularización. Tanto uno como otro, educados a finales de la década de los sesenta y principios de la de los setenta, se habían visto obligados a asimilar la «tesis de la secularización» en el transcurso de su formación profesional. Ambos sabían por experiencia propia que dicha tesis era inadecuada en el mejor de los casos, y simplemente errónea en el peor -un punto de vista que los acontecimientos posteriores vendrían a confirmar con fuerza abrumadora- Pero eso no les ahorraría tener que aprender dicha tesis, dado que formaba parte de una educación «correcta» y resultaba necesaria si querían obtener la titulación imprescindible para el ejercicio de sus respectivas carreras. La situación empírica que tan bien conocían quedó simplemente arrumbada: la teoría adquiría preponderancia sobre los datos (2007-11:13-14)".

\section{Contextos diferentes en Europa y América Latina (y algunas coincidencias).} Algunos aspectos de la vida académica

Es importante destacar que existe en la filosofía una corriente de pensamiento denominada "la filosofía después de Auschwitz". Theodor Adorno lo sintetizó diciendo que "escribir poesía después de Auschwitz en un acto de barbarie". Esta propuesta tiene un correlato en América Latina: "Lo que define a 'La Filosofía después de Auschwitz en Latinoamérica' es la elección y el tratamiento de los temas que aborda. Los pensadores latinoamericanos examinan el grado de participación del conocimiento en los procesos negativos de la modernidad. Para enfrentar esta situación han buscado, en sus propias tradiciones, desarrollos del pensamiento que se hayan gestado como expresiones de resistencia a la dominación. Desde esta reflexión crítica se está construyendo una 
racionalidad emancipatoria que finque su universalidad en la diversidad de la experiencia humana”. (Pilatowsky, 2007:302)

El nazismo tuvo la peculiaridad de configurarse como un gobierno designado por procedimientos electorales relativamente transparentes para la época, que decidió el exterminio de las disidencias políticas (socialistas y comunistas) para luego continuar con el exterminio de pueblos completos (judíos, gitanos y otros), además de minorías sexuales y religiosas (homosexuales y Testigos de Jehová), negando a los masacrados toda condición humana y lo más escandaloso es que tuvo la capacidad de involucrar en esto al pueblo alemán y a sectores significativos de otros pueblos, como acepto recientemente (7 de julio de 2017) el presidente Macrón la participación de Francia y del Estado Francés en el Holocausto. (https://internacional.elpais.com/internacional/2017/07/16/ actualidad/1500207654_147039.htm). Nunca es tarde, aunque sean 73 años después que los franceses enviaran al exterminio a los judíos franceses.

\section{Los intentos de homogeinizar la pluralidad}

Cabe mencionar el involucramiento de las derechas latinoamericanas en las actividades y propuestas de Hitler y la admiración que ganara este en ciertos sectores conservadores de la Región, quienes en la década de los setenta re-aparecerían respaldando y participando en los regímenes de "seguridad nacional" en América Latina. Esto es soslayado por muchos analistas latinoamericanos. Olga Wornatt (2002:143-230-231) documentó la presencia de obispos y sacerdotes en los campos de tortura y exterminio de los militares argentinos durante los años del Proceso. Algo similar exhibe el Informe Nunca Más, de la Comisión Sábato (CONADEP, 1985), que también documentó el asesinato de dos obispos, sacerdotes y agentes de pastoral por los militares del Proceso, con el beneplácito de la mayoría del Episcopado Argentino, lo mismo sucedió en El Salvador con el asesinato del Arzobispo Romero. Ambos documentos describen el papel de los sacerdotes capellanes militares participando activamente en la tortura y desaparición de personas. Llama la atención que el comportamiento de los militares argentinos al asesinar al Obispo Angellelli de la Rioja, Argentina, es semejante al de los militares franquistas alzados en armas contra la República Española, quienes en los años 30 ejecutaron a sacerdotes vascos y navarros que se oponían a sus planes, con el acuerdo de la Iglesia Católica española (Equiza, 2010-12). Los militares salvadoreños hicieron lo propio con Romero, Rutilio Grande, los jesuitas de la UCA y un largo etcétera.

El rechazo de la dialéctica religión-religiosidades me lleva a cuestionar el concepto de religión popular o catolicismo popular o religiosidad popular, en general nadie conoce toda su religión, excepto algún teólogo hipotético, sino que toma una "parte del arco de posibilidades" (Benedict, 1944-1971:15, 49, 56), lo que existe entonces es un pluralismo católico, una diversidad de sistemas religiosos, diferentes entre sí, que se identifican 
como las partes de una totalidad diversa y relativamente consistente. Del mismo modo en América Latina existe un pluralismo evangélico que se define como heredero de la Reforma Luterana, que adoptan la macro-denominación de cristianos y que se oponen al mundo católico y a su interior se escinden en diversas denominaciones o en estructuras que rechazan la nomenclatura denominacional. Estas realidades son inimaginables para los sociólogos-teólogos que describí e inaplicables para sus discípulos locales, pues "todo lo que no entra" en sus categorías eurocéntricas es "inexistente".

Es muy importante la autocrítica que hace el sociólogo de las religiones francés Olivier Roy tratando de comprender los errores de los investigadores sobre el Islam y su incapacidad para prever y en muchos casos explicar a posteriori el 11 de septiembre, señala que: "los especialistas han utilizado paradigmas erróneos, (por ejemplo, las teorías desarrollistas según las cuales la modernización seguía un camino paralelo al de la secularización) y, por lo tanto no han contribuido en nada a la comprensión de la violencia radical" (Roy, 2003:91).

Algo similar sucede en el contexto argentino, Elmer S. Miller reconoce que se equivocó cuando en sus trabajos de 1970 planteaba que los misioneros cristianos que actuaban entre los Tobas de Argentina desarrollaban una secularización, en una revisión publicada en 2003 explica que subestimó la capacidad de los Tobas de reelaborar y apropiarse para fortalecer sus estrategias de fortalecimiento de su identidad y autodeterminación (Miller, 2003:15).

\section{Las "estrategias" de la Iglesia Católica}

En nuestro análisis debemos mencionar la influencia de la Iglesia Católica española franquista en la formación de las elites religiosas, políticas, sociales, económicas y militares de América Latina, cuya expresión institucional eran los Institutos de Cultura Hispánica que operaban en América Latina, a los que debemos agregar multitud de seminarios españoles donde se formaron muchos sacerdotes latinoamericanos. Esto es posible de visualizar en las políticas de exterminio de las disidencias políticas esbozadas por la dictadura de Pinochet, los militares del Proceso en Argentina, Stroessner en Paraguay, El Salvador, Guatemala, Honduras, para citar algunos casos, donde los militares se arrogaron el derecho de exterminar físicamente a cualquier oposición política, En Brasil, la dictadura militar instaurada en 1964 fue reforzada por los capellanes militares tanto católicos como protestantes (bautistas y presbiterianos), el contexto de legitimación golpista era la lucha contra el "comunismo internacional" (Silveira Campos, 2014:177, Dias, 2014).

La Iglesia Católica dejo pendientes los grandes problemas y trató de resolverlo mediante una renovación institucional, el aggiornamiento del Concilio Vaticano II implicó muchas 
novedades, pero también la respuesta integrista y restauracionista de San Juan Pablo II, quien reafirmó la hipótesis de no ceder a los cambios, para evitar que se deteriorara más la institución, ese freno al aggiornamiento incrementó el deterioro del catolicismo institucional. Manteniendo un conjunto de oposiciones que implicaba volver sobre sí mismos, sin estar dispuestos ni a "aprender mucho y (ni a) olvidar mucho". El restauracionismo católico quedó congelado en la Guerra Fría, sin entender que pasó “después de la Caída del Muro de Berlín”(1989).

\section{Las iglesias nacionales latinoamericanas y los Estados}

En este contexto es importante observar que las respectivas iglesias nacionales, presionadas desde la Santa Sede, en el período de San Juan Pablo II, apoyaron el exterminio de los disidentes, sin dejar de mencionar, pues sería injusto la oposición minoritaria de algunos obispos en Argentina, Romero en El Salvador, entre otros y ciertas órdenes y congregaciones religiosas. Está documentado el apoyo de los gobiernos españoles (y su Iglesia) a las dictaduras latinoamericanas, aún en "democracia”. Sintetizando, podemos afirmar qué las iglesias latinoamericanas, desde un modelo de Iglesia de Estado, salvo honrosas excepciones, apoyaron decididamente a estos regímenes dictatoriales que replicaban el "modelo franquista". Incluso en un período extenso la Iglesia Católica mexicana se lanzó decididamente a la "lucha anticomunista". Cuando la Iglesia Católica planteó la des-constantinización de la Iglesia en América Latina, la Jerarquía quedó en una situación anómica que fue rápidamente resuelta por la oposición y desmantelamiento del Concilio Vaticano II por San Juan Pablo II. La relación de la Santa Sede y las iglesias nacionales con la política del Departamento de Estado norteamericano fue evidenciada en las filtraciones de los Wikileaks. (https://actualidad.rt.com/actualidad/view/91138wikileaks-vaticano-eeuu-pinochet).

\section{Lo que las iglesias de Estado no percibieron}

La Iglesia Católica Jerárquica se dedicó en forma entusiasta a fortalecer una restauración preconciliar, designando obispos anti-Concilio Vaticano II y desmantelando las comunidades eclesiales de base de la Teología de la Liberación Latinoamericana, además de eliminar la posibilidad de consagrar sacerdotes de esta tendencia, quienes fueron sistemáticamente excluidos de los seminarios. Del mismo modo, se reforzó la relación de las elites religiosas con las elites económicas, políticas y militares, transformándose de Iglesia Católica en un "seguro ideológico" del sistema, después de los escarceos de la Teología de la Liberación. Las jerarquías católicas pensaban que podían mantener su hegemonía "desde las cúpulas", catolizando a las cúpulas del poder y desde allí aplicar "la teoría del goteo", que estas cúpulas se transformarían en modelos de identificación de las "bases de la sociedad". 
Hubo ciertas variables que las cúpulas nunca tomaron en cuenta. Son varias y podemos comenzar por el proceso de construcción y reproducción del clero. Es un lugar común hablar de la crisis de vocaciones sacerdotales y de religiosos y religiosas. La caída ha sido en términos absolutos y relativos, a lo cual se agrega el envejecimiento del personal, para decirlo en términos demográficos, agotó el bono demográfico y la tasa de reproducción, para el caso mexicano es del 0.6. En términos concretos por cada tres sacerdotes que fallecen, sólo habrá dos que los reemplacen, incrementándose notablemente el coeficiente de católicos por sacerdote, a lo cual se le deben agregar el agravante del envejecimiento del personal, más el hecho de que muchos sacerdotes, particularmente los religiosos no están al frente de parroquias, sino en actividades propias de la orden o congregación respectiva.

El agotamiento del bono demográfico se asocia con el control natal, que implica una desobediencia sistémica a la Encíclica Humanae Vitae (Paulo VI, 25/7/1968), las familias urbanas tienen entre 1 y 3 hijos promedio, esto implica qué si un hijo o hija opta por el celibato, el esquema de reproducción familiar sufre una catástrofe. Cuando las familias tenían entre 8 y 12 hijos, el celibato sacerdotal de hijas e hijos "segundones" era un alivio en las presiones hereditarias. Pero en las zonas rurales, las tasas de nacimiento son más altas. Esta situación ha llevado a una ruralización del clero mexicano, como comentó el Arzobispo Víctor SánchezEspinosa el 18 de marzo de2015.(http://intoleranciadiario.com/ detalle_noticia/131420/ciudad/ordena-arzobispo-victor-cuatro-nuevos-sacerdotes)

La situación es que hay diócesis donde los sacerdotes deben atender un promedio de 20,000 feligreses. Antes la falta de sacerdotes se paliaba con la captación de europeos, en la actualidad en dicho continente la baja de vocaciones es más notable e incluso la iglesia católica alemana ordenó a sus sacerdotes destacados en América Latina, regresar a sus diócesis de incardinación para reforzar el trabajo local. Muchos episcopados han fortalecido el desarrollo de la ordenación de diáconos permanentes casados, que están en alrededor de 45,000. Otros episcopados nacionales se oponen a estos y exigen permanecer con personal célibe, aunque Francisco lanzó la propuesta de ordenar como sacerdotes a viri probatii (hombres casados) como sacerdotes, lo que rebasará, de aprobarse, a los diáconos. También está proponiendo un Sínodo para la Amazonía, donde se propone desarrollar una Iglesia Autóctona, con indígenas casados ordenados sacerdotes. En términos conceptuales esto ya había sido planteado por el antropólogo y sacerdote Manuel M. Marzal SJ, hace más de 50 años (1973:107-123)

http://www.lastampa.it/2017/06/03/vaticaninsider/es/en-el-mundo/amazonia-agendapara-un-snodo-Lxl6dGDFh8ZMVkNHhg6TrI/pagina.html 
Esta propuesta apuntaría a un desarrollo similar en Chiapas, donde después de orar frente a la tumba de Samuel Ruíz se comprometió a profundizar su propuesta pastoral de iglesia autóctona (Marzal, 1992, 1994).

\section{Tendencias en el campo político religioso. Cuando el panadero es malo, le echa la culpa a la harina. (Dicho popular)}

La Jerarquía Católica atribuye labaja de vocaciones sacerdotales y religiosas, la disminución de los bautizos y casamientos religiosos a la consolidación del relativismo de los valores y la crisis de los mismos en la sociedad contemporánea, nada más equivocado: lo que se fortalece en las sociedades latinoamericanas son movimientos religiosos de carácter evangélico y pentecostal, que se caracterizan por tendencias fundamentalistas basadas en la aplicación literal de los textos bíblicos, además de tener características apocalípticas y milenaristas. Sin descartar por supuesto la consolidación de personas no creyentes. Desde esta perspectiva, la Jerarquía Católica lanzó este diagnóstico, el relativismo de los valores para ocultar su incapacidad de proponer valores o más precisamente, para no reconocer el empoderamiento de estas antiguas minorías religiosas, que ya son mayoría en varios países latinoamericanos. La tendencia, y esto está perfectamente claro en el análisis de las estadísticas de bautizos y casamientos religiosos, confrontados con la información de nacimientos y matrimonios civiles (Masferrer, 2012, 2013), es que queda poco del continente católico que recibió Juan Pablo II hace treinta y ocho años, esto se ratifica con las encuestas anuales que hace Latino Barómetro.

La Jerarquía lejos de reconocer su fracaso, acusa de libertinos a los fieles que defeccionan, pero la información etnográfica muestra otra cosa; quienes abandonan el catolicismo lo hacen mayoritariamente hacia propuestas religiosas más rígidas y exigentes en materia moral, ética y de valores.

\section{El desafío de las metrópolis y las megalópolis. Los modelos de Iglesia.}

Los obispos callaron a las comunidades eclesiales de base y otras formas de participación de los feligreses haciendo énfasis en más clericalismo. Fue notoria la incapacidad de la Jerarquía Católica para involucrar a los jóvenes en actividades institucionales. Los evangélicos han desplegado un conjunto de estrategias pastorales muy pertinentes para llegar a los jóvenes y a los matrimonios "en construcción y en vías de consolidación", esto asociado a un conjunto de propuestas viables en zonas urbanas, metropolitanas y megalópolitanas.

La instauración del catolicismo en América Latina se hizo durante el período colonial y se afianzó sobre la base de una posición monopólica, de religión de estado y de complemento de la empresa colonial. La Iglesia Católica operó en la construcción de identidades locales, regionales y luego nacionales para la población. Cualquier intento de 
pluralidad religiosa era acallado con la amenaza de la Inquisición. Sin embargo, el "pacto colonial” (Halperín Donghi, 1977) hizo crisis a fines del siglo XVIII y con ello disminuyó sustantivamente el poder eclesiástico tornándolo obsoleto, situación que se agudizó con las independencias nacionales. En el siglo XIX las iglesias a nivel nacional se lanzaron a proponer, con relativo éxito, imágenes religiosas que fueran patrones de las nacientes naciones de la Región.

En el siglo XX el modelo entró nuevamente en crisis, pues de origen estos santos y vírgenes patrones estaban íntimamente ligados con los procesos agrícolas, con los ciclos de siembra y cosecha. Esta base simbólica eminentemente agraria no supo ser replanteada en términos simbólicos para las complejidades de la vida urbana, el sistema de santos y vírgenes no aparece como modelo identitario y surgen nuevas propuestas. Desde los símbolos nacionales hasta ciertos personajes que se transforman en modelos identitarios para las nuevas generaciones como: John Lennon, el Che Guevara, Michel Jackson, Madonna, Justin Bieber y una larga lista de ídolos juveniles y generacionales.

Los evangélicos han logrado posicionar "héroes musicales", la mayoría conversos que renuncian públicamente a su vida de pecadores y "reciben a Cristo", como Yuri, Marco Antonio Barrientos, Marcela Gándara, Fermín IV de Control Machete, ahora pastor en la Iglesia Semilla de Mostaza y una larga lista que se engrosa constantemente, además de aquellos que nacieron en el seno de las iglesias evangélicas como Marcos Witt. A través de la música los evangélicos se han posicionado entre los jóvenes con una perspectiva, si no ecuménica, al menos transdenominacional.

Estrenos de diversos formatos de música cristiana

\begin{tabular}{|c|c|c|}
\hline \multirow{2}{*}{ Tipo de lanzamiento } & \multicolumn{2}{|c|}{ Lanzamientos } \\
\cline { 2 - 3 } & $\mathbf{2 0 1 3}$ & $\mathbf{2 0 1 4}$ \\
\hline Álbum & 303 & 276 \\
\hline Viodeclip & 217 & 175 \\
\hline Sencillo & 267 & 285 \\
\hline EP's & 14 & 22 \\
\hline Total & 584 & 583 \\
\hline
\end{tabular}

Fuente: Alianza de radios cristianas en español. Proceso Diana Ramos G. 


\section{La cuestión urbana en América Latina}

Las ciudades durante el siglo XIX eran espacios administrativos, sedes de las autoridades políticas y eclesiásticas o puertos de contacto con el exterior. Esta situación se mantuvo relativamente, pero después de la Primera Guerra Mundial y con más intensidad durante la Segunda Guerra Mundial se aplicaron políticas de industrialización por sustitución de importaciones, y la vida urbana en América Latina se diversificó exponencialmente. Si bien no se dieron integraciones verticales en las industrias como resultado de la dependencia de los países metropolitanos, exteriores a nuestra Región, es evidente que se establecieron centros cada vez más complejos de desarrollos industriales, financieros y de servicios. Como consecuencia de las políticas desarrollistas de los años cincuenta del siglo pasado se consolidaron espacios metropolitanos como Rio de Janeiro, Sao Pablo, Recife y Porto Alegre en Brasil, Buenos Aires, Córdoba y Rosario en Argentina, Santiago en hile, Lima, Chimbote y Trujillo en Perú, Guayaquil y Quito en Ecuador, Caracas, Maracaibo y Mérida en Venezuela, Medellín, Cali y Bogotá en Colombia y ciudad de México, Guadalajara y Monterrey en México. Además de grandes ciudades en todos los países de América del Sur y América Central. Estas grandes ciudades y áreas metropolitanas, en algunos casos se transformaron en megalópolis, como es el caso de ciudad de México, Sao Paulo y Buenos Aires.

La nueva situación implicó muchas cuestiones hasta el momento desconocidas e imposibles de prever por los sociólogos formados en las entreguerras y que mantuvieron su hegemonía hasta fines del siglo XX, dicho modelo de hegemonía cultural se prolonga en sus discípulos quienes muchas veces tienen "miedo al cambio". No vamos a enumerar todos los cambios sucedidos, pero es importante señalar algunos: Complejización de la estratificación social y desarrollo de pirámides sociales "paralelas", segmentación horizontal y vertical de la sociedad, descomposición de las familias extensas muy características de las sociedades agrarias, como resultado de la migración nacional e internacional, la búsqueda y construcción de otras formas de relación social, la configuración de "guettos" urbanos localizados y transversalizados. Dificultades para acceder a la información y fortalecimiento de los anonimatos y soledades estructurales, la definición de nuevas enfermedades mentales y neurosis como resultado de la vida en las metrópolis y megalopolis.

\section{La respuesta de las iglesias}

Cómo los procesos de metropolización y megapolización coincidieron con el período restauracionista preconciliar de Juan Pablo II, la Iglesia Católica mantuvo una estrategia hacia las multitudes, de servicios religiosos masivos y rutinarios, mientras que se centraban en "la atención personalizada" a las elites políticas, sociales, económicas, militares y del mundo del espectáculo, "la gente de la farándula", dirían en México, llegaron a instalar 
capellanes en las dos empresas del duopolio televisivo, estas eran atendidas por los legionarios y se articulaba con otras Órdenes y Congregaciones religiosas especializadas en escuelas y universidades de elite, como Legión de Cristo, Maristas, La Salle, Opus Dei, Jesuitas, Salesianos, entre otros. Una de las propuestas católicas más creativas y exitosas fue la configuración del culto a San Judas Tadeo en el Centro Histórico de la ciudad de México, parte de su éxito es que la celebración es mensual y no anual, desligándose de cualquier ciclo agrícola y con una excelente ambigüedad instrumental, el Señor de las causas imposibles. (Macías, 2018)

\section{Algunas propuestas para los próximos años en la investigación}

Mi hipótesis de trabajo es que estamos frente a una disputa histórica por la memoria y la construcción de nuevas utopías. Ante la crisis del proyecto neoliberal y la inviabilidad de la utopía del socialismo real se consolida una disputa por los modos de consumo, las grandes masas de las diferentes sociedades se encuentran frente a un sistema que sólo tiene opciones para un número limitado de personas: "el simbólico 1\% frente al 99\%" que mencionaba el movimiento de Ocupa Wall Street. Ante esta crisis estructural, donde además el $1 \%$ tiene capacidad de bloquear al 99\%. Se concentra la disputa en el campo simbólico y en la memoria profunda, el tiempo estructural, confrontado con la larguísima duración, que planteara Braudel. Eso en términos de teología confronta la Tradición de las Iglesias, los modos sacramentales; contra la búsqueda de la legitimidad en los Tiempos Bíblicos, planteados como un retorno a las Escrituras.

Lo más notable para el trabajo de los antropólogos de las religiones es que la construcción de los imaginarios sociales y culturales se dan en la "lectura" de los Textos sagrados y su aplicación al tiempo corto, a una estrategia para guiar los comportamientos en el contexto de esta crisis cultural, social, económica y religiosa. Si observamos el catolicismo, Francisco y sus seguidores, que son muchos, reclaman su legitimidad en las Escrituras, mientras que la Curia y quienes la apoyan, se basan en la Tradición. El campo evangélico se escinde en diferentes lecturas también y oscila entre los que revisan el Éxodo, hasta los que buscan el control político o Dominionismo (Aguilar de la Cruz, 2019), los planteos de la derecha cristiana, se propone el control del gobierno civil a través de la acción política, para establecer una nación gobernada por cristianos. Su fundamento es Génesis 1:26 "Y dijo Dios: Hagamos al hombre a nuestra imagen, conforme a nuestra semejanza; y ejerza dominio sobre los peces del mar, sobre las aves del cielo, sobre los ganados, sobre toda la tierra, y sobre todo reptil que se arrastra sobre la tierra.

En su particular lectura, la Iglesia es el representante de Dios y por lo tanto esta debe subordinar el gobierno de los hombres, estos planteos son la base de la llamada Nueva Reforma Apostólica (Wynarczyk, 2009, 2010), fundamento de las llamadas megaiglesias y los teleevangelistas y ciertos sectores de la derecha católica. Debemos entender qué entre 
los evangélicos, al igual que entre los católicos se expresan una multiplicidad de planteos y toda generalización reduccionista es peligrosa en cualquier proceso de investigación y de explicación de la realidad.

Debemos entender que ante los pueblos y sociedades que investigamos atraviesan por una crisis profunda resultado del fracaso de las utopías que orientaban las acciones humanas y estas sociedades están en la búsqueda de nuevas utopías posibles. El desafío de los antropólogos en sociedades complejas consiste en el desarrollo de propuestas conceptuales, teóricas y metodológicas que nos permitan explicar las nuevas realidades de las transformaciones en el mundo rural, de los procesos de urbanización y megalopolización, que escinden las sociedades latinoamericanas en núcleos cada vez más diversos y complejos, plurales, multiculturales y que construyen sistemas religiosos distintos que reflejan las nuevas realidades culturales, donde los intentos de simplificación llevan a procesos reduccionistas que no nos podemos permitir. 


\section{REFERENCIAS BIBLIOGRÁFICAS}

AGUILAR de la CRUZ, Hedilberto (2019). Indígenas evangélicos en las ciudades de México y Lima. Transformaciones étnicas, mestizaje y participación sociopolítica. Tesis de doctorado en Estudios Latinoamericanos, UNAM, CDMX

ASSMAN, Jan (2006). La distinción mosaica o el precio del monoteísmo. Madrid: AKAL. ----- (2008). Religión y memoria cultural. Diez estudios. Buenos Aires: Libros de la Araucaria-LILMOD.

(2014). Violencia y monoteísmo. Barcelona: Fragmente.

ENEDICT, Ruth (1971). El hombre y la cultura (Patterns of culture). Penguin. Buenos Aires: CEAL.

BRAUDEL, Fernand (1980). La historia y las ciencias sociales. Madrid: Alianza.

COMISIÓN NACIONAL SOBRE LA DESAPARICIÓN DE PERSONAS (CONADEP) (1985). Nunca más. Informe de la Comisión Nacional sobre la Desaparición de Personas. Buenos Aires: EUDEBA.

DAVIE, Grace (2011). Sociología de la religión. Madrid: Akal.

DOBBELAERE, Karel (1994). Secularización. Un concepto multidimensional. México: Castellana.

EQUIZA, Jesús (2012). Los sacerdotes navarros ante la represión de 1936-1947 y ante la rehabilitación de los fusilados. Berriozar, Navarra, Cenlit Ediciones.

GEERTZ, Clifford (1989). La interpretación de las culturas. Barcelona: GEDISA.

HALPERIN, Tulio (1977). Historia contemporánea de América Latina. Madrid: Alianza. MACÍAS RODRÍGUEZ, Rolando (2018) "Hace posible lo imposible” El señor de las causas desesperadas. San Judas Tadeo en América Latina (Tesis de doctorado), México, ENAH

MARZAL, Manuel M. (1973). ¿Es posible una iglesia indígena en el Perú?. América Indígena, XXXIII-1(III), 107-123.

----- (1992). La utopía posible. Indios y jesuitas en la América colonial (1549-1767). Lima, Pontificia Universidad católica del Perú.

----- (Comp.) (1994). El rostro indio de Dios. México: CRT-UIA.

MASFERRER, Elio (2004). ¿Es del Cesar o es de Dios? Un modelo antropológico del campo religioso. México: CIICH-UNAM-Plaza y Valdés. 
----- (2009). Religión, poder y cultura. Ensayos sobre la política y la diversidad de creencias. Buenos Aires-México: Libros de la Araucaria.

----- (2011). Pluralidad religiosa en México. Cifras y proyecciones. Buenos Aires-México: Libros de la Araucaria.

----- (2014). Religión, política y metodologías. Aportes el estudio de los sistemas religiosos. México: Libros de la Araucaria.

MATE, Reyes (2007). Introducción. En MATE, Reyes \& Ricardo FORSTER. El judaísmo de Iberoamérica. Enciclopedia iberoamericana de religiones (9-23). Madrid: Trotta

MILLER, Elmer S. (2003). Secularization Theory reconsidered. Perspectives from the Argentine Chaco. Acta Americana, 11-2, 5-18.

NUN, José (1970), "Superpoblación relativa, ejército industrial de reserva y masa marginal", en Revista Latinoamericana de Ciencias Sociales, núms. 1 y 2, Santiago de Chile.

----- (2001), Marginalidad y exclusión social, FCE, México.

PIKETTY, Thomás (2015). El capital en el siglo XXI. México: FCE.

PILATOWSKY, Mauricio (2007). La filosofía después de Auschwitz en Latinoamérica. En MATE, Reyes \& Ricardo FORSTER. El judaísmo de Iberoamérica. Enciclopedia iberoamericana de religiones (279-303). Madrid: Trotta.

ROY, Olivier (2003). El Islam globalizado. Los musulmanes en la era de la globalización. Barcelona: Bellaterra.

----- (2003). Después del 11 de septiembre. Islam, antiterrorism y orden internacional. Barcelona: Ediciones Bellaterra.

SILVEIRA CAMPOS; Leonildo (2014): Os Evangélicos, o Golpe e a Ditadura: O irresistível Canto das Sereias Autoritárias En Dias, Zwinglio Mota (Org.) Memórias ecumênicas protestantes - Os protestantes e a Ditadura: colaboração e resistência. Rio de Janeiro: KOINONIA Presença Ecumênica e Serviço, pp. 177-191, 2014.

WYNARCZYK, Hilario (2009). Ciudadanos de dos mundos. El movimiento evangélico en la vida pública argentina 1980-2001. San Martín: UNSAM EDITA, Universidad Nacional de San Martín.

----- (2010). Sal y luz de las naciones. Evangélicos y política en la Argentina (1980-2001). Buenos Aires: Instituto di Tella/Siglo XXI. 
WORNAT, Olga (2002). Nuestra Santa Madre. Historia pública y privada de la Iglesia Católica Argentina. Buenos Aires: Ediciones B. 